\title{
The publication trend of neuropathic pain in the world and China: a 20-years bibliometric analysis
}

\author{
Jishi Ye ${ }^{1+}$, Huang Ding ${ }^{1+}$, Juan Ren ${ }^{2}$ and Zhongyuan Xia ${ }^{1 *}$
}

\begin{abstract}
Background: There has been tremendous change on neuropathic pain research in the past 20 years in China and around the world. We analyzed the global trend of neuropathic pain research and compared China's quantity and quality of neuropathic pain-related publications with other developed countries.

Methods: Using terms "neuropathic pain", we retrieved related publications from the Web of Science (WOS) database and PubMed database. From different aspects, such as the number of papers, total citations, average citations per item, H-index, research types, orientation, institutions, journals and funding, global neuropathic pain publications were classified and analyzed.

Results: From 1998 to 2017, 21,733 articles regarding neuropathic pain research were published worldwide. Of these, 9.394\% were contributed by authors from Chinese institutions, which followed USA and ranked second. However, the quality indicators of publications, including total citations, average citations per item and H-index, were relatively low in China. High contribution journals and the 10 most-cited articles on neuropathic pain in world and China were also listed, which also can reflect the quality of neuropathic pain. Based on National Natural Science Foundation of China (NSFC), basic research was the main articles type, accounting for 32.91\% of China's neuropathic pain research.

Conclusion: Global neuropathic pain research increased rapidly during the 1998 to 2017 period. The USA was still the leader of neuropathic research. Although China had made great achievements, there was a significant gap in the high-quality studies between China and other leading countries.
\end{abstract}

Keywords: Bibliometric analysis, China, PubMed, Neuropathic pain, Web of science

\section{Introduction}

Neuropathic pain, a pain syndrome caused by a lesion or disease of the somatosensory system, is a major public health concern and becoming the global burden [1-3]. Epidemiological research showed that the prevalence of neuropathic pain is likely to lie between $6.9 \%$ and $10 \%$ and cost increases year by year $[4,5]$. According to site of major pathology, the classification of neuropathic pain also includes pathology, peripheral, spinal and brain [6]. Yet, few studies, until now, have uncovered the precise mechanism and a therapeutic

\footnotetext{
* Correspondence: xiazhongyuan2005@aliyun.com

† Jishi Ye and Huang Ding contributed equally to this work.

1 Department of Anesthesiology, Renmin Hospital of Wuhan University, No.

99 Zhang Road, Wuhan 430060, Hubei, People's Republic of China
}

Full list of author information is available at the end of the article approach. In the past two decades, innumerable research and money focused on this field to make clear the underling mechanism of neuropathic pain and therapeutic target. Meanwhile, many related research results were published in all kinds of journals in the form of articles [7-9]. Along with the tremendous economic growth, China' scientific strength grows rapidly and achieves great accomplishments in neuropathic pain field. However, current studies have not shown the global and China's development trend regarding neuropathic pain yet.

Bibliometrics is concerned with the analysis of research based on citation counts and patterns. This method can be used to evaluate the influence of an individual research output, such as a journal article, or a 
collection of research outputs, such as all works by a particular author, research group or institution. Different fields, such as anesthesiology [10], respiratory medicine [11], urology [12], and cancer [13] have performed this method to measure and rank research output both within institutions and on a national or international level.

To evaluate the quantity and quality of global neuropathic pain research, we utilized the bibliometrics analysis to analyze the research progress and growing trend in this field during two decades 2008-2017. At the same time, we also compared the neuropathic pain publications records from Chinese institutions and other developed countries to make clear the China's contribution to neuropathic pain research and a gap in the quality of publications between China and other developed countries.

\section{Methods}

\section{Data sources}

This study was conducted based on previous similar publications. All data were acquired on September 20, 2018. Consider that these data were downloaded from the public databases and there existed no ethical questions about them, we did not apply the ethical approval. Neuropathic pain-related articles published between 1998 and 2017 were retrieved from PubMed database and the Web of Science (WOS) online database, which included the Science Citation Index Expanded (SCIE), Social Sciences Citation Index (SSCIE) and Arts \& Humanities Citation Index(A\&HCI). The journal impact factors (IF) came from Journal Citation Reports 2015 database. Foundation data from China were derived from the Latest scientific fund results query system (http://www.letpub.com.cn/index.php?page=grant). In addition, research types, including randomized controlled trials (RCTs), clinical trials, and case reports, were retrieved from the PubMed database.

\section{Search strategy}

In WOS, the search terms were: Theme $=$ (neuropathic pain) AND publishing year $=(1998-2017)$. Literature type included article, review, meeting abstract, proceedings paper and letter. In PubMed, the search terms were: Mesh $=$ (neuropathic pain) AND publication date (1998/01/01-2017/12/31). Literature type included basic research, randomized controlled trials, clinical trials and case reports. To search for basic research, we identified the species as "other Animals." Publication quality was assessed by using total citations frequency, average citations per item and $\mathrm{H}$-index. Literature quantity and publication trend were analyzed by total publications, research types, research orientations, research organization, author's contribution, journal and funding support.

\section{Statistical analysis}

Descriptive statistical analyses were mainly used. Trends during the two decades studied were analyzed using linear regression by SPSS 12.0 (SPSS Inc., Chicago, IL, USA). $P$ values less than 0.05 were considered significant.

\section{Results}

Neuropathic pain related articles in world and in China

Based on search criteria, a total of 21,733 articles were published in world from 1998 to2017 in WOS database. The global number of publications regarding neuropathic pain displayed a positive growth trend $\left(\mathrm{R}^{2}\right.$ $=0.9776, P<0.01$ ), from 320 in 1998 to 2723 in 2017 . Nearly 99 countries/regions participated in global neuropathic pain research. Among them, the USA published the largest number of neuropathic pain articles $(9589,35.341 \%)$, followed by China (2549, 9.394\%), England (2254, 8.307\%), Germany (2183, $8.046 \%)$, and Japan $(2183,8.046 \%)$. Like global publication trend, the annual publications of neuropathic pain in these countries all showed a remarkably positive trend (Fig. 1a-d).

In China, a total of 2549 articles on neuropathic pain were published between 1998 to 2017 and showed a strongly growth as well $\left(R^{2}=0.7853, P<0.01\right)$. Among all provinces, Beijing produced the most papers in the past two decades (Fig. 1e-f).

\section{Citations and $\mathrm{h}$-index analysis in world and China}

According to the WOS database, neuropathic pain papers from the USA possessed most frequently citations, with 347,125 total citations and average 36.2 citations per item during the past 20 years. In terms of the $\mathrm{H}$-index, the index of the USA was 213, which was higher than that of any other country or region (Fig. 2a). Despite the number of articles ranked the second, the total citations and $\mathrm{H}$-index of papers published in China (31,148 total citations, 12.22 citations per item and $60 \mathrm{H}$-index) were behind other developed countries.

One thousand three hundred sixty eight institutions from different nations or regions contributed to neuropathic pain research between 1998 and 2017. The top 13 most contributing institutions in the world are listed in Fig. 2b. Among these institutions, 9 were from the USA, University of Oxford was in UK, University of Toronto was from Canada, Karolinska institution was from Sweden and Aarhus University Hospital was in Denmark. The institution with the largest amount of neuropathic pain articles was Harvard University, which produced 550 papers and had 46,432 total citations and 104 h-index. In China, Fourth Military Medical University ranked first, which published 191 


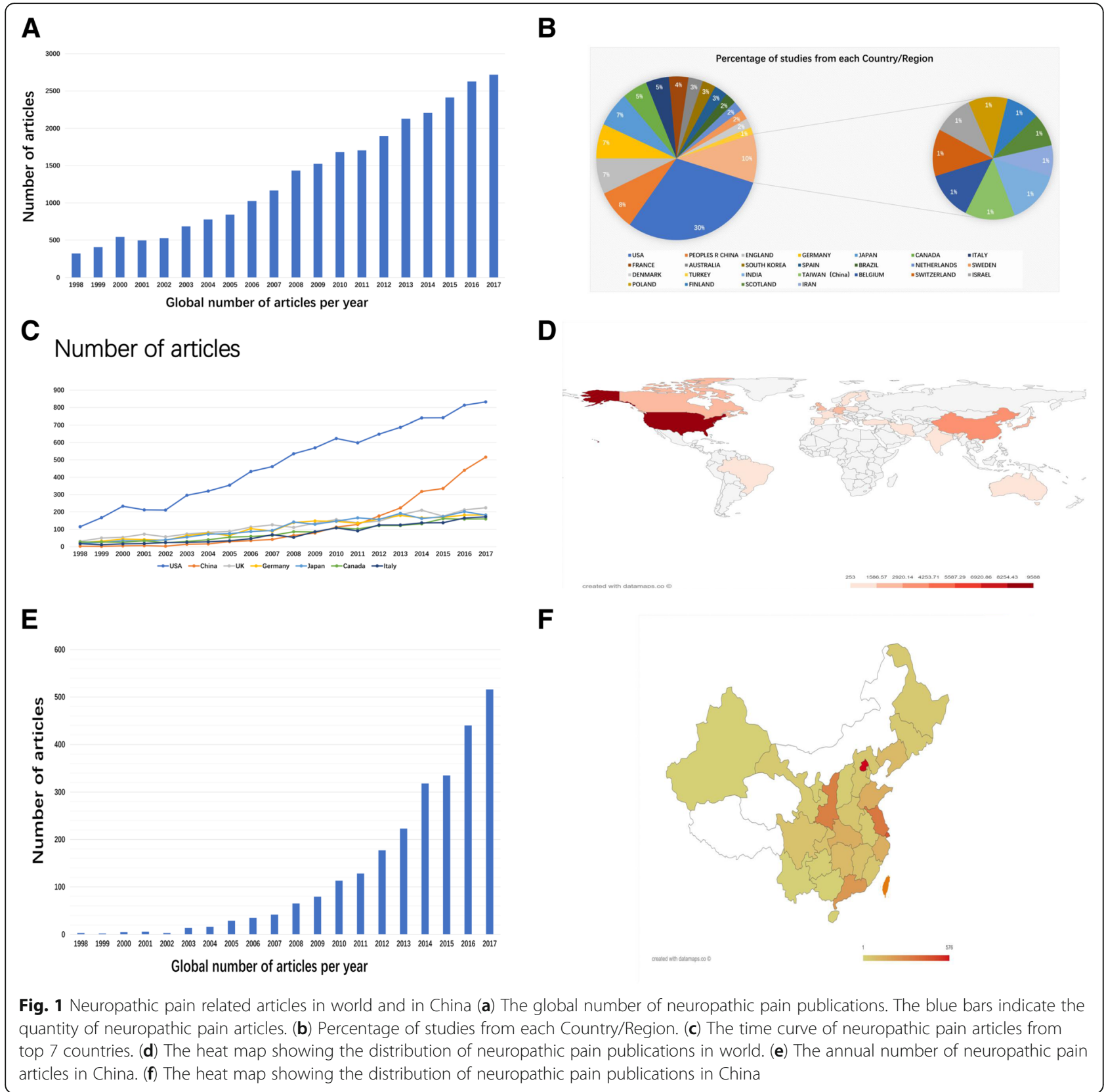

papers with 3361 total citations and $33 \mathrm{H}$-index (Fig. 2c). Obviously, there is a huge gap between the world's top institutions and Chinese institutions regarding on neuropathic pain. And these differences should not be ignored.

\section{The difference of research categories and article types in world and China}

In world, there were 127 research categories on neuropathic pain articles, among which neuroscience neurology $(13,425,49.491 \%)$, pharmacology $(4883,18.001 \%)$, anesthesiology (4550, 16.774\%), general internal medicine (1831, 6.75\%), and biochemistry molecular biology $(1466,5.404 \%)$ were the most common areas (Fig. 3a). In this regard, the research categories of Chinese articles on neuropathic pain are similar with the global articles (Fig. 3b).

In the past 20 years, global researchers mainly focused on basic research with 8967 papers, accounting for $32.91 \%$ of the total neuropathic papers in PubMed database (Fig. 3c). And the growth rate keeps increase. Additionally, 3258 case reports (11.94\%), 1752 clinical trials $(6.42 \%)$, and 1190 RCTs (4.36\%) were published in the neuropathic pain field. The amount of papers 


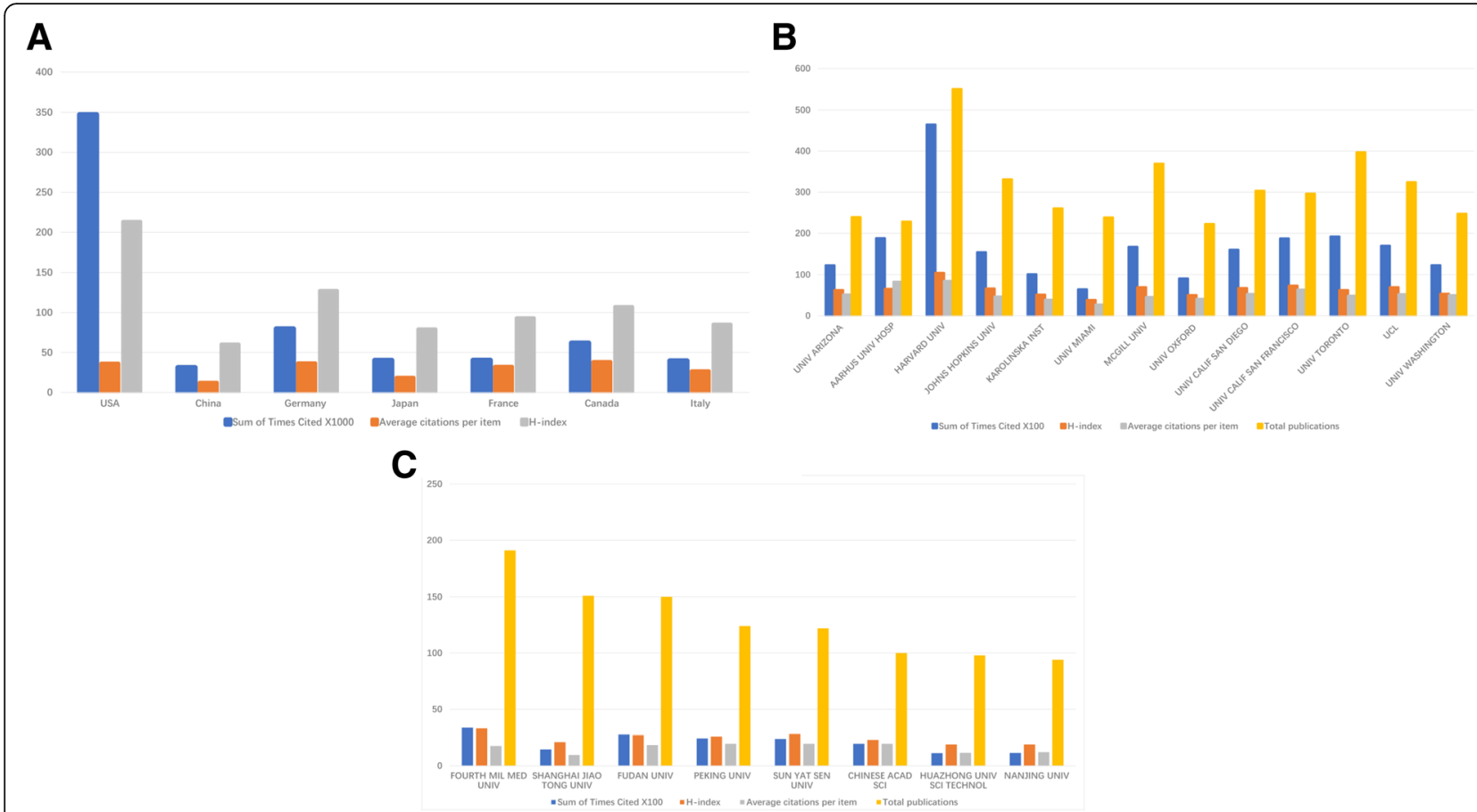

Fig. 2 Citations and h-index analysis in world and China (a) The total citations, average citations per paper and H-index for neuropathic pain articles from top countries. (b) The total citations, average citations per paper and H-index for neuropathic pain articles in the global institutions. (c) The total citations, average citations per paper and $\mathrm{H}$-index for neuropathic pain articles in Chinese institutions

A

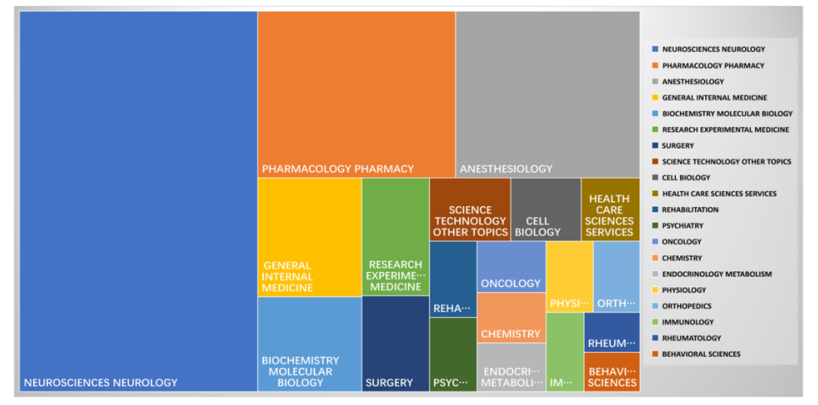

\section{C}

\section{Number of articles}

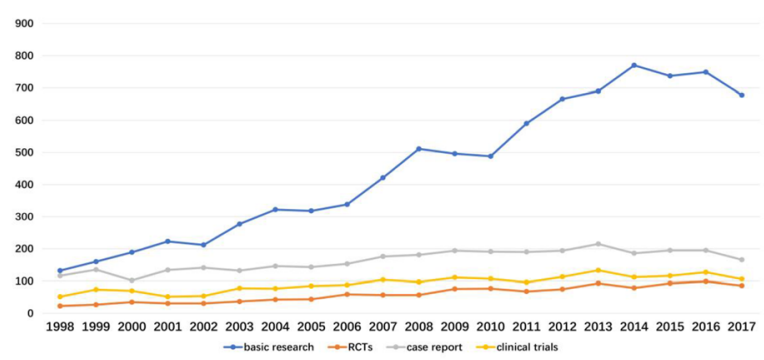

B

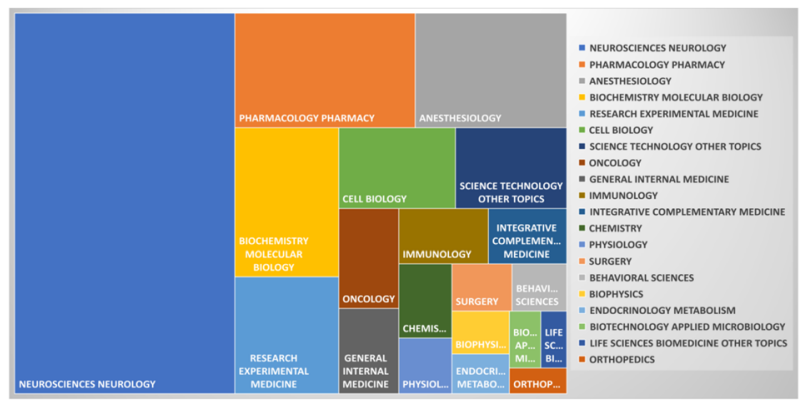

D

\section{Number of articles}

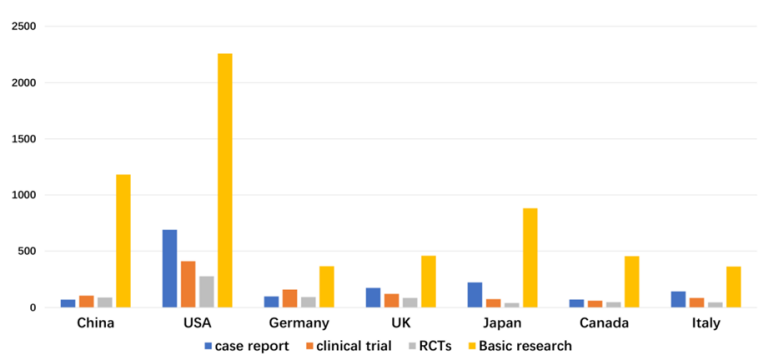

Fig. 3 The difference of research categories and article types in world and China (a) The research categories on neuropathic pain in world. (b) The research categories on neuropathic pain in China. (c) The article types analysis regarding neuropathic pain in the past two decades worldwide. (d) The article types analysis regarding neuropathic pain from top countries in the past two decades 
for each research types from the USA far exceed other countries. Although China ranked second, the gap is still considerable (Fig. 3b).

\section{High contribution journals in neuropathic pain field and funds in China}

In neuropathic pain field, PAIN is the most contribution journal in the world with the largest number of publications and highest H-index. For China, Molecular Pain produced the largest number of paper, with 117 neuropathic pain papers, accounting for $4.59 \%$ of the total, followed by Neuroscience Letters (101, $3.962 \%)$ and Pain $(76,2.982 \%)$ (Figs. 3a-c and $4 \mathrm{a}-\mathrm{c}$ ).

In China, National Natural Science Foundation of China (NSFC) was the main Chinese funding organization, which reflected the scientific capability of research institutions. The fund supplied a total of
134 projects and 52.551 million RMB for neuropathic pain research in the past 20 years, with a strong growth trend (for amount of projects: $\mathrm{R}^{2}=0.7958, P$ $<0.01$; for money: $R^{2}=0.7706, P<0.01$ ), indicating that neuropathic pain field gradually gained official attention and support. Among them, Sun Yat-Sen University obtained 7.27 million RMB funding of NSFC, followed by Central South University (3.16 million RMB) and Nanjing Medical University (3.07 million RMB) (Figs. 3d-e and 4d-e).

\section{The 10 most-cited articles on neuropathic pain in world and China}

The top 10 articles are listed in Tables 1 and 2. The number of citations for the global top 10 articles ranged from 1060 to 2147, while the most-cited paper in China only cited 504 times. The top 10 articles in both

\section{A}

Number of articles

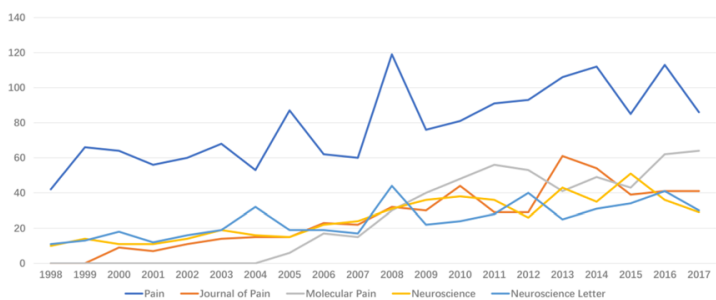

B
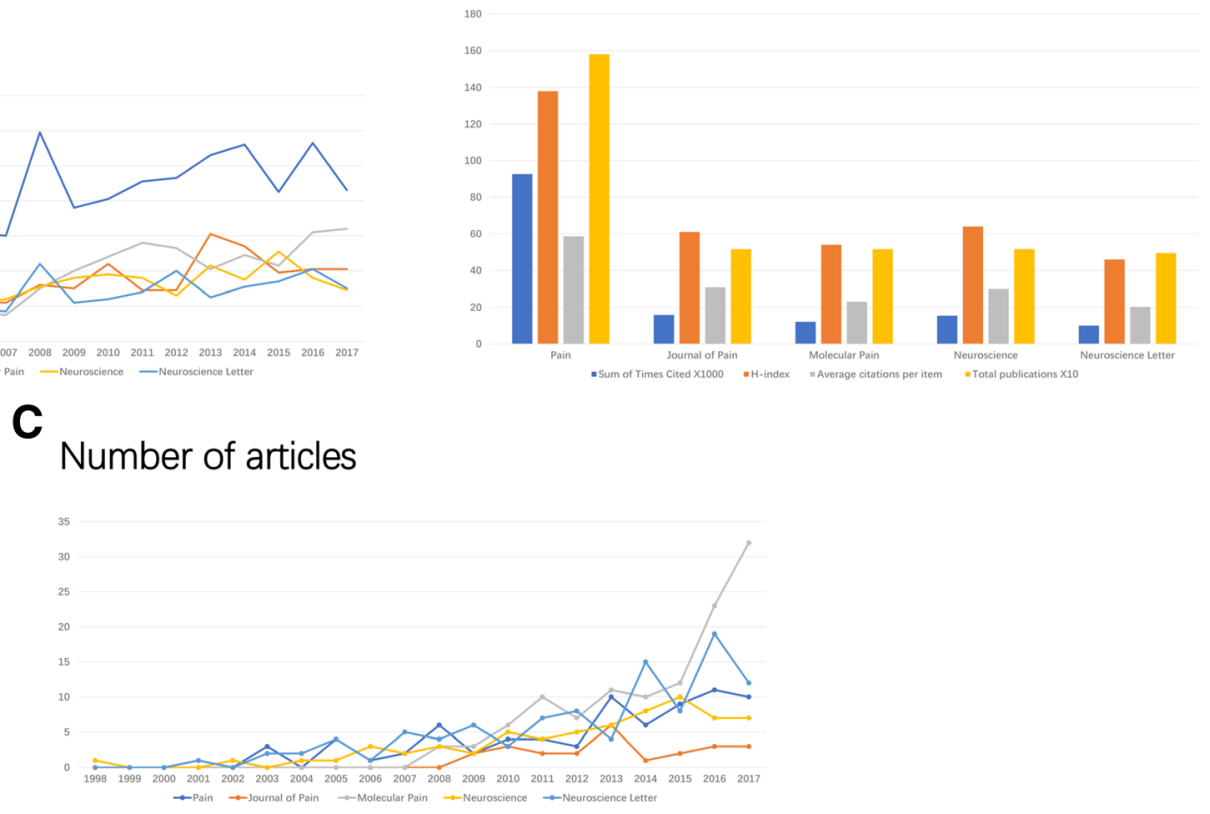

D

E

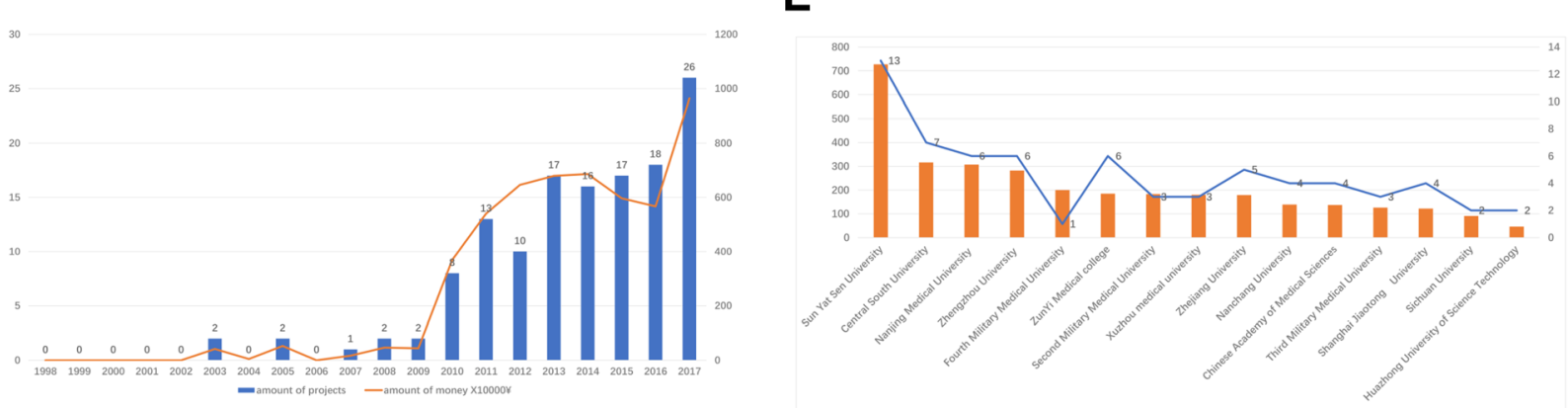

Fig. 4 High contribution journals in neuropathic pain field and funds in China (a) The top5 high contribution journals in neuropathic pain field. (b) The number of articles for 5 main neuropathic pain journals in world. (c) The number of articles for 5 main neuropathic pain journals in China. (d) The time curves for NSFC funding in past 20 years. (e) NSFC funding of neuropathic pain research at different Chinese institutions 
Table 1 The Top 10 most frequently cited articles on neuropathic pain in the world

\begin{tabular}{|c|c|c|c|c|c|}
\hline Title & Author & Journal & Year & IF & $\begin{array}{l}\text { Times } \\
\text { cited }\end{array}$ \\
\hline Neuroscience - Neuronal plasticity: Increasing the gain in pain & Woolf, CJ et al & SCIENCE & 2000 & 41.058 & 2147 \\
\hline Persistent postsurgical pain: risk factors and prevention & Kehlet, $\mathrm{H}$ et al & LANCET & 2006 & 53.254 & 1470 \\
\hline $\begin{array}{l}\text { Core outcome measures for chronic pain clinical trials: } \\
\text { IMMPACT recommendations }\end{array}$ & Dworkin, $\mathrm{RH}$ et al & PAIN & 2005 & 5.559 & 1422 \\
\hline $\begin{array}{l}\text { Neuropathic pain: aetiology, symptoms, mechanisms, and } \\
\text { management }\end{array}$ & Woolf, CJ et al & LANCET & 1999 & 53.254 & 1309 \\
\hline $\begin{array}{l}\text { Neuropathic pain - Redefinition and a grading system for } \\
\text { clinical and research purposes }\end{array}$ & Treede, R.-D et al & NEUROLOGY & 2008 & 7.609 & 1247 \\
\hline Cellular and Molecular Mechanisms of Pain & Basbaum, Allan I et al & CELL & 2009 & 31.398 & 1224 \\
\hline $\begin{array}{l}\text { Central sensitization: Implications for the diagnosis and treatment of } \\
\text { pain }\end{array}$ & Woolf, Clifford J. & PAIN & 2011 & 5.559 & 1190 \\
\hline Monocyte Chemoattractant Protein-1 (MCP-1): An Overview & $\begin{array}{l}\text { Deshmane, Satish L et } \\
\text { al }\end{array}$ & $\begin{array}{l}\text { JOURNAL OF INTERFERON } \\
\text { AND CYTOKINE RESEARCH }\end{array}$ & 2009 & 2.419 & 1138 \\
\hline $\begin{array}{l}\text { Central Sensitization: A Generator of Pain Hypersensitivity by } \\
\text { Central Neural Plasticity }\end{array}$ & $\begin{array}{l}\text { Latremoliere, Alban et } \\
\text { al }\end{array}$ & JOURNAL OF PAIN & 2009 & 4.859 & 1107 \\
\hline $\begin{array}{l}\text { Pharmacologic management of neuropathic pain: Evidence- } \\
\text { based recommendations }\end{array}$ & $\begin{array}{l}\text { Dworkin, Robert } \mathrm{H} \text { et } \\
\text { al }\end{array}$ & PAIN & 2007 & 5.559 & 1060 \\
\hline
\end{tabular}

world and China mainly published from 1999 to 2014, while none were published in the latest three years (2015-2017). In addition, compared that the global top 10 papers are all reviews, the top10 most-cited papers included 5 articles, 4 reviews and 1 brief communication.

\section{Discussion}

In our studies, we completed a bibliometric study of the scientific publications in global neuropathic pain research and analyzed the China's achievement and gap in neuropathic pain field in the last 2 decades, which helped us to comprehend the global scientific trend in neuropathic pain and the direction of the scientific and technological innovation in China. In the past 20 years, neuropathic pain research had made a continuous and rapid growth in number of papers at world level. Like its economic power, the USA held the first place in every category, with largest publications and citations and highest $\mathrm{H}$-index. The scientific research and development are still unbalanced, and

Table 2 The Top 10 most frequently cited articles on neuropathic pain in China

\begin{tabular}{|c|c|c|c|c|c|}
\hline Title & Author & Journal & Year & IF & $\begin{array}{l}\text { Times } \\
\text { cited }\end{array}$ \\
\hline $\begin{array}{l}\text { Cytokine mechanisms of central sensitization: Distinct and overlapping role of } \\
\text { interleukin-1 beta, interleukin-6, and tumor necrosis factor-beta in regulating } \\
\text { synaptic and neuronal activity in the superficial spinal cord }\end{array}$ & $\begin{array}{l}\text { Kawasaki, Yasuhiko } \\
\text { et al }\end{array}$ & $\begin{array}{l}\text { JOURNAL OF } \\
\text { NEUROSCIENCE }\end{array}$ & 2008 & 5.970 & 504 \\
\hline Neural mechanism underlying acupuncture analgesia & Zhao, Zhi-Qi & $\begin{array}{l}\text { PROGRESS IN } \\
\text { NEUROBIOLOGY }\end{array}$ & 2008 & 14.163 & 394 \\
\hline Acupuncture and endorphins & Han, JS & $\begin{array}{l}\text { NEUROSCIENCE } \\
\text { LETTERS }\end{array}$ & 2004 & 2.159 & 360 \\
\hline $\begin{array}{l}\text { Identification of gene expression profile of dorsal root ganglion in the rat } \\
\text { peripheral axotomy model of neuropathic pain }\end{array}$ & Xiao, HS et al & PNAS & 2002 & 9.504 & 342 \\
\hline Emerging targets in neuroinflammation-driven chronic pain & Ji, Ru-Rong et al & $\begin{array}{l}\text { NATURE REVIEWS } \\
\text { DRUG DISCOVERY }\end{array}$ & 2014 & 50.167 & 196 \\
\hline Brain cannabinoid CB2 receptors modulate cocaine's actions in mice & Xi, Zheng-Xiong et al & NATURE NEUROSCIENCE & 2011 & 19.912 & 170 \\
\hline $\begin{array}{l}\text { Down-regulation of mu-opioid receptors in rat and monkey dorsal root } \\
\text { ganglion neurons and spinal cord after peripheral axotomy }\end{array}$ & Zhang, $X$ et al & NEUROSCIENCE & 1998 & 3.338 & 145 \\
\hline $\begin{array}{l}\text { The role of tumor necrosis factor-alpha in the neuropathic pain induced } \\
\text { by Lumbar } 5 \text { ventral root transection in rat }\end{array}$ & $\mathrm{Xu}$, Ji-Tian et al & PAIN & 2006 & 5.559 & 141 \\
\hline Emerging role of Toll-like receptors in the control of pain and itch & Liu, Tong et al & $\begin{array}{l}\text { NEUROSCIENCE } \\
\text { BULLETIN }\end{array}$ & 2012 & 3.155 & 138 \\
\hline $\begin{array}{l}\text { Spinal glial activation in a new rat model of bone cancer pain produced by } \\
\text { prostate cancer cell inoculation of the tibia }\end{array}$ & $\begin{array}{l}\text { Zhang, RX et al. } \\
\text { Berman, BM; Lao, LX }\end{array}$ & PAIN & 2005 & 5.559 & 132 \\
\hline
\end{tabular}


developed countries are leading the global neuropathic pain trend. China scored a tremendous achievement in neuropathic pain field. However, compared to articles published by other leading countries, the quality of China's papers still needs to be improved. In terms of articles type, same as the world, Chinese researchers also focused more attention on basic research with more output. Accompanied by official attention and support, neuropathic pain related NSFC funding became more and more, which enhanced the development of China' scientific research further.

Amazing achievement were acquired in global neuropathic pain research, with 320 papers in 1998 increasing to 2723 in 2017, which inspired those people suffered from pain with neuropathic characteristics. Based on these researches and outcomes, neuropathic pain was classified more and more accurate, and its several important contributory mechanisms included abnormal discharge in nociceptive nerves, peripheral and central sensitization, chronic and pathological activation of microglia, and impaired inhibitory modulation [6]. Current treatment still recommended antidepressants (tricyclic agents and serotonin-norepinephrine reuptake inhibitors) and anticonvulsants (gabapentin and pregabalin) as first-line treatments [4]. Individualized multidisciplinary patient care provided new direction for neuropathic pain, which may cause further advancements to neuropathic pain research in the future.

In the early decade, neuropathic pain research in China seemed to be faltering, but burst after 2010, reaching 223 articles in 2013, which ranked second in the world and was in accordance with NSFC funding assistance in 2010. The following reasons may explain this phenomenon: The scientific research power is based on economic strength. The world's second largest economy boosted the neuropathic pain research in the past 20 years in China, which was also demonstrated by many bibliometric studies of other disciplines. The NSFC is a barometer of scientific research investments in China. Besides these funding of national level, most of the provinces would increase the supporting funding in neuropathic pain following national science and technology policy, such as provincial or municipal natural science fund key projects. It is because of these policy and funding that more and more talented person returned to China with advanced concept and techniques and promoted the international cooperation on neuropathic pain diagnosis and treatments. Additionally, the huge population base is a precious resource for clinical trial in neuropathic pain in China. That is why clinical trials and random controlled trials increased rapidly in the last ten years. However, completed clinical database and analysis system should be planned to unite and integrate these independent different hospital and massive amount of clinical resource.
Except for quantity increase, we should emphasize the quality of publications. For the citations frequency and h-index, there exists still a considerable gap between China and other developed countries. Compared to ourselves, our quality of neuropathic pain publications had improved. But it need more time to catch up other leading countries. At first, China should continue to introduce the top talents and leading professors to construct high quality neuropathic pain research platform and multi-center studies. In our bibliometric analysis, no Chinese institutions could rank into top20 contributing institutions. No experts, no institutions. Second, consideration that there is no top pain related journal from China, several international journals on neuropathic pain should be created in China so as to attract more submissions and spread academic perspective. Based on these situations, China still has great potential to grow in publications quality.

Obviously, there are some limitations in our analysis. Firstly, some research outcomes may involve in international collaboration with different countries. Our retrieved results of institutional affiliations could cause bias in the study. Second, on account of "neuropathic pain" as subject term, we may ignore some papers, such as those indexed with "chronic pain". Third, some articles collection from WOS and PubMed database may be delayed so that citations and $\mathrm{H}$-index exist flaw.

\section{Conclusion}

At world level, neuropathic pain research had made impressive growth in volume during the last 20 years. The USA is still the leader of neuropathic pain research both in quality and quantity. In the past two decades, China gradually became a critical force on neuropathic pain research. However, compared with the publications quantity growth, there is still a considerable gap in research quality between China and other leading countries. Therefore, there is still a long way to go, China need take measure to complete high-quality neuropathic pain studies.

\section{Abbreviations \\ A\&HCl: Arts \& Humanities Citation Index; IF: impact factors; NSFC: National Natural Science Foundation of China; RCTs: randomized controlled trials; SCIE: Science Citation Index Expanded; SSCIE: Social Sciences Citation Index; WOS: Web of Science}

\section{Acknowledgements \\ We thank the Central Laboratory (Renmin Hospital of Wuhan University) for the equipment and excellent technical assistance.}

\section{Fundings}

This study was supported by the National Natural Science Foundation of China (Grant No. 81671891). 


\section{Availability of data and materials}

The datasets analyzed during the current study are available from the corresponding author on reasonable request.

\section{Author contributions}

All authors contributed toward data analysis, drafting and revising the paper and agree to be accountable for all aspects of the work. All authors reviewed and approved the final version of the manuscript.

\section{Ethics approval and consent to participate}

Not applicable.

\section{Consent for publication}

Not applicable.

\section{Competing interests}

All authors declare that they have no conflict of interests to state.

\section{Publisher's Note}

Springer Nature remains neutral with regard to jurisdictional claims in published maps and institutional affiliations.

\section{Author details}

'Department of Anesthesiology, Renmin Hospital of Wuhan University, No. 99 Zhang Road, Wuhan 430060, Hubei, People's Republic of China. 2Department of Respiratory, Wuhan general hospital of the People's liberation Army, Wuhan 430060, Hubei, People's Republic of China.

Received: 2 October 2018 Accepted: 1 November 2018

Published online: 15 November 2018

\section{References}

1. van Hecke O, Austin SK, Khan RA, Smith BH, Torrance N (2014) Neuropathic pain in the general population: a systematic review of epidemiological studies. Pain 155(4):654-662

2. Guevara-López U, Covarrubias-Gómez A, García-Ramos G, HernándezJiménez S (2006) Practice guidelines for neuropathic pain management. Rev Investig Clin 58:126-138

3. Jensen TS, Baron R, Haanpää M et al (2011) A new definition of neuropathic pain. Pain 152:2204-2205

4. Gilron I, Baron R, Jensen T (2015) Neuropathic pain: principles of diagnosis and treatment. Mayo Clin Proc 90(4):532-545

5. Mayoral V, Pérez-Hernández C, Muro I, Leal A, Villoria J, Esquivias A (2018) Diagnostic accuracy of an identification tool for localized neuropathic pain based on the IASP criteria. Curr Med Res Opin 34:1465-1473

6. Cohen SP, Mao J (2014) Neuropathic pain: mechanisms and their clinical implications. BMJ 348:f7656

7. Teles AR, Ocay DD, Shebreen AB et al (2018) Evidence of impaired pain modulation in adolescents with idiopathic scoliosis and chronic back pain. Spine J

8. Schou WS, Ashina S, Amin FM, Goadsby PJ, Ashina M (2017) Calcitonin gene-related peptide and pain: a systematic review. J Headache Pain 18:34

9. Truini A (2015) Trigeminal neuralgia. J Headache Pain 16:A42

10. Xie G, Zhang K, Wood C, Hoeft A, Liu J, Fang X (2016) China's contribution to anesthesiology research: a 10-year survey of the literature. Anesth Analg 122(5):1640-1645

11. Ye B, Du T, Xie T et al (2014) Scientific publications in respiratory journals from Chinese authors in various parts of North Asia: a 10-year survey of literature. BMJ Open 4(2):e004201

12. Rezaee ME, Johnson HA, Munarriz RM, Gross MS (2018) Bibliometric analysis of erectile dysfunction publications in urology and sexual medicine journals. J Sex Med

13. Zhu H, Yang X, Qin Q et al (2014) Report of China's innovation increase and research growth in radiation oncology. Chin J Cancer Res 26(3):293-298

Ready to submit your research? Choose BMC and benefit from:

- fast, convenient online submission

- thorough peer review by experienced researchers in your field

- rapid publication on acceptance

- support for research data, including large and complex data types

- gold Open Access which fosters wider collaboration and increased citations

- maximum visibility for your research: over $100 \mathrm{M}$ website views per year

At $\mathrm{BMC}$, research is always in progress.

Learn more biomedcentral.com/submissions 